\title{
INVESTIGATIONS TO HYGROSCOPIC AEROSOL GROWTH WITHIN THE CONVECTIVE BOUNDARY LAYER
}

\author{
Dietrich Althausen $^{1}{ }^{*}$, Andrew Reigert ${ }^{2}$, Ulla Wandinger ${ }^{1}$, Jens Reichardt ${ }^{3}$ \\ ${ }^{1}$ Leipniz Institute for Tropospheric Research, 04318 Leipzig, Germany \\ ${ }^{2}$ Bertrandt Ing-.Büro GmbH, 85080 Gaimersheim, Germany \\ ${ }^{3}$ German Meteorological Service, Aßmann Observatory, Lindenberg, Germany \\ *Email:dietrich@tropos.de
}

\begin{abstract}
We present a new method to determine the hygroscopic growth of atmospheric particles. This method combines lidar measurements with high temporal resolution of the particle backscatter coefficient and water vapor mixing ratio with temperature measurements from radiosondes and a microwave radiometer. The hygroscopic growth is described by an equation that represents the two observed branches of the growth curve with different dependencies on the relative humidity. An example is presented to illustrate a first result from a continental air mass case.
\end{abstract}

\section{INTRODUCTION}

Hygroscopic particle growth capabilities are immanent properties of atmospheric particles. As particles grow and change their sizes, the lidar aerosol optical properties are influenced. This influence is deeply dependant on the different measured aerosols properties, especially their chemical composition.

These particle properties are only accessible by simultaneous measurements of their respective particle optical properties and the relative humidity with a high temporal resolution and within the same atmospheric volume. Especially, such investigations have to ensure that the measurements are performed for the same atmospheric particle type at different values of relative humidity.

The dependence of the particle growth on relative humidity has been investigated for a long time [1-5]. But these investigations were done by laboratory studies or by in-situ measurements. [6-7] investigated hygroscopic growth along a horizontal optical path in $30 \mathrm{~m}$ height above the ground. These comprehensive investigations were performed at unperturbed atmospheric humidity conditions. They showed the applicability of the parametrization scheme, but were limited to the ground and the current humidity conditions there.

This study investigates the hygroscopic growth of particles in the well mixed daytime planetary boundary layer. It is realized by combining vertical measurements of lidar aerosol optical properties and relative humidity.

\section{METHODOLOGY}

\subsection{Enhancement factor of the particle backscatter coefficient}

The hygroscopic growth is characterized by the increase of the particle backscatter coefficient $\beta_{\text {par }}$ in dependence on the relative humidity $\phi$ and is described by the enhancement factor

$$
f(\phi)=\frac{\beta_{\mathrm{par}}(\phi)}{\beta_{\mathrm{par}}(\phi=40 \%)} .
$$

This enhancement factor is determined by a no linear fit to the measurement data by using the following equation and the fit parameters $\phi_{\mathrm{thr}}, a_{0}$, $a_{1}$, and $E_{2}$ :

$$
f(\phi)= \begin{cases}a_{0}\left(1-\frac{\phi}{100}\right)^{-E_{1}} & \text { for } \phi \leq \phi_{\mathrm{thr}} \\ a_{0} a_{1}\left(1-\frac{\phi}{100}\right)^{-E_{2}} & \text { for } \phi>\phi_{\mathrm{thr}}\end{cases}
$$

where $E_{1}=E_{2}-\frac{\ln \left(a_{1}\right)}{\ln \left(1-\frac{\phi_{\mathrm{thr}}}{100}\right)}$. 


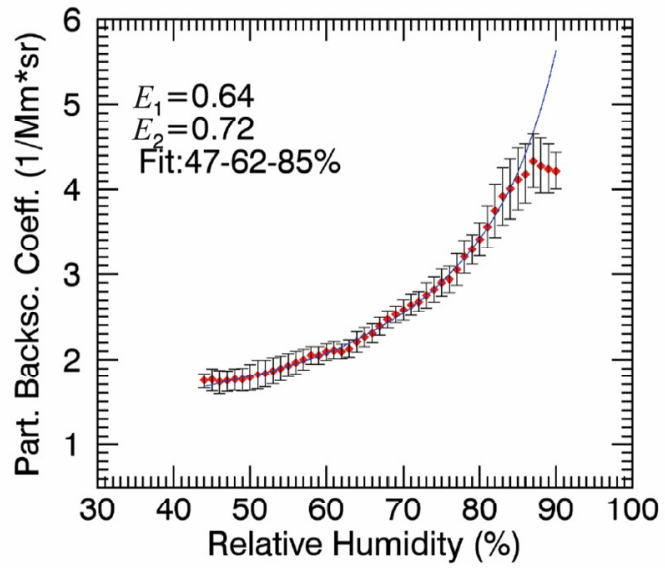

Fig. 1. Particle backscatter coefficient in dependence on relative humidity, 13 August 2015.

This approach takes into account that atmospheric aerosol is usually comprised of particles across several size ranges (size distribution) and different types (chemical composition). Hence, there is often no single deliquescence or fluorescence relative humidity identifiable.

\subsection{The lidar system}

We used the RAMSES (Raman lidar for atmospheric moisture sensing) system of the German Meteorological Service [8] for the determination of the particle backscatter coefficient and the water vapor mixing ratio. This ensures the observation of the same atmospheric column with varying humidity at a high temporal resolution. The RS-92 (Vaisala) radiosondes, launched every 6 hours, provided the data for the calibration of the lidar's water vapor mixing ratios and temperature profiles. The microwave radiometer MP-3039A from the Radiometrics Corporation (radiometrics.com) supplied temperature measurements between the radiosonde launches. By combining both temperature measurements using weighing functions and applying the result to the lidar's water vapor mixing ratio the relative humidity was determined. All measurements were taken at the Lindenberg Meteorological Observatory "Richard Aßmann" (52 12'29.29"N, 14 $\left.7^{\prime} 11.01 " \mathrm{E}\right)$.



Fig. 2. Enhancement factor in dependence on relative humidity, 13 August 2015.

\section{FIRST RESULTS}

Figures 1 and 2 show the particle backscatter coefficient and the enhancement factor from 13 August 2015. The threshold relative humidity is $62 \%$ on this day. The height of the convective planetary boundary layer was approximately $1.8 \mathrm{~km}$. Backward trajectories show an east-northeast air mass advection, which suggests a continental aerosol mixture with a strong regional influence.

\section{REFERENCES}

[1] H. Köhler, Trans. Faraday Soc., 32, 1152-1161 (1936)

[2] C. Orr et al., Journal of Atmospheric Sciences 15, 240-241 (1958)

[3] F. Kasten, Tellus, 21, 631-635 (1969)

[4] G. Hänel, Advances in Geophysics, 19, 74 (1976)

[5] P. Zieger et al., Tellus B, 66 (2014)

[6] A. Skupin et al. Atmospheric Measurement Techniques 7, 701-712 (2014)

[7] A. Skupin et al., Atmospheric Chemistry \& Physics, 16, 1863-1876 (2016)

[8] J. Reichardt et al., Appl. Optics, 51 (34), 8111-8131 (2012) 